\title{
KAJIAN FAKTOR LINGKUNGAN DAN IDENTIFIKASI FILUM MOLLUSCA, FILUM ECHINODERMATA DI EKOSISTEM PADANG LAMUN PERAIRAN PANTAI NEGERI TULEHU KABUPATEN MALUKU TENGAH
}

\author{
Stevin Melay ${ }^{1}$, P.M.J. Tuapattinaya ${ }^{1}$, Fatimah Sangadji ${ }^{2}$ \\ 1Staf Pengajar Program Studi Pendidikan Biologi FKIP Unpatti \\ ${ }^{2}$ Alumni Pendidikan Biologi FKIP Unpatti \\ E-mail: melaystevin@yahoo.com
}

\begin{abstract}
Background: Bodies of State Tulehu a coastal region that has seagrass which adjoins the living marine resources such as mangroves, algae, molluscs, and others. Seagrass in the coastal waters of State Tulehu has spread widely. Information about environmental factors in seagrass ecosystems is still limited that affect its structure. Therefore, to investigate environmental factors and identify the types of phyla phylum molluscs and echinoderms in coastal waters Tulehu village.

Methods: The study was conducted in August 2014 by using the quadrant method by using purposive sampling. Hasil environmental research shows physical factors (temperature, $\mathrm{pH}$, salinity, and dissolved oxygen) varies in each quadrant with the results of the identification of Echinodermata and mollusk species also varies.

Results: The second research station results obtained 4 types of echinoderms which 1 represents the class Asteroidea species, one species representing Ophiuroidea class, and two types represent the class Echinoidea. On this study, 4 types of echinoderms are divided into three classes, namely class Asteroidea, class Ophiuturoidea, and this Echinoidea. Next class described the types of echinoderms are found on both the research station is Archaster typicus, Ophiocoma erinaceus, Diadema setosum and Laganum depressum. From 3 classes found in both types of Archaster typicus research stations which are found because berhabitat sandy.

Conclusion: In the second research station found found four species of the phylum of echinoderms were included in three classes, namely class Echinoidea (sea urchins) are represented by two types, class Asteroidea (starfish) represented by one type and class Ophiuroidea (brittle stars) represented one kind, moreover, In the second research station also found 19 Type molluscs which consists of two types of class Bivalvia and 17 species of the class Gastropoda.
\end{abstract}

Key words: identification, environmental factors, phylum of mollusks, the phylum Echinodermata, ecosystem.

\begin{abstract}
Abstrak
Latar Belakang: Perairan Negeri Tulehu merupakan wilayah pesisir yang memiliki ekosistem lamun yang berdampingan dengan sumber daya hayati laut yang lainnya seperti mangrove, algae, mollusca, dan lain-lain. Ekosistem lamun pada perairan pantai Negeri Tulehu memiliki penyebaran yang cukup luas. Informasi faktor lingkungan di ekosistem padang lamun tersebut masih terbatas yang memepengaruhi strukturnya. Oleh karena itu dilakukan penelitian untuk mengetahui faktor lingkungan dan mengidentifikasi jenis-jenis dari filum mollusca dan filum echinodermata di perairan pantai negeri Tulehu.

Metode: Penelitian dilakukan pada Agustus 2014 dengan menggunakan metode kuadran dengan teknik purposive sampling. Hasil penelitian menunjukkan factor fisik lingkungan (suhu, $\mathrm{pH}$, salinitas, oksigen terlarut) bervariasi pada tiap kuadran dengan hasil identifikasi jenis Echinodermata dan molusca yang bervariasi pula.

Hasil: kedua stasiun penelitian hasil yang didapatkan 4 jenis echinodermata yaitu 1 jenis mewakili kelas Asteroidea, 1 jenis mewakili kelas Ophiuroidea, dan 2 jenis mewakili kelas Echinoidea. Pada penelitian ini didapatkan 4 jenis echinodermata yang terbagi menjadi 3 kelas yaitu kelas Asteroidea, kelas Ophiuturoidea, dan kelas Echinoidea.Berikut ini diuraikan jenis-jenis echinodermata yang ditemukan pada kedua stasiun penelitian yaitu Archaster typicus, Ophiocoma erinaceus, Diadema setosum dan
\end{abstract}


Laganum depressum. Dari 3 kelas yang ditemukan pada kedua stasiun penelitian jenis Archaster typicus yang banyak ditemukan karena berhabitat yang berpasir.

Kesimpulan: Pada kedua stasiun penelitian ditemukan ditemukan 4 jenis dari filum echinodermata yang termasuk dalam 3 kelas yaitu kelas Echinoidea (bulu babi) diwakili oleh 2 jenis, kelas Asteroidea (bintang laut) diwakili oleh 1 jenis dan kelas Ophiuroidea (bintang mengular) diwakili 1 jenis. Selain itu, pada kedua stasiun penelitian juga ditemukan 19 Jenis Mollusca yang terdiri dari 2 jenis dari kelas Bivalvia dan 17 jenis dari kelas Gastropoda.

Kata Kunci: identifikasi, faktor lingkungan, filum mollusca, filum Echinodermata, ekosistem.

\section{PENDAHULUAN}

Ekosistem lamun atau yang dikenal sebagai padang lamun (Seagrass beds) merupakan salah satu ekosistem yang terletak didaerah pesisir atau perairan laut dangkal. Komunitas lamun terletak antara batas terendah pasang surut sampai kedalaman tertentu dimana matahari masih mencapai dasar (Khouw, 2008). Lamun adalah tumbuhan berbiji tunggal (Monokotil) dari kelas Angiospermae (Kordi, 2011). Fungsi padang lamun antara lain sebagai perangkap sedimen, menstabilkan substrat dasar dan menjernihkan air, produktivitas primer, sumber makanan langsung bagi kebanyakan hewan, habitat beberapa jenis hewan air, dan sebagai substrat bagi organisme penempel (Fonseca et al., 1982; Fonseca \& Cahalan, 1992). Padang lamun mendukung kehidupan biota yang cukup beragam dan berhubungan satu sama lain, dimana jaringan makanan yang terbentuk antara padang lamun dan biota lain adalah sangat kompleks (McRoy \& Helfferich, 1980; Klumpp et al., 1989). Pada ekosistem lamun, hidup beranekaragam biota laut seperti echinodermata (teripang, bulu babi, dan bintang laut), moluska, polikaeta, krustasea (udang dan kepiting) dan ikan.

Heni (2007), mengemukakan bahwa hewan makrobenthos mempunyai sifat yang relatif menetap dan mempunyai pergerakan yang sangat terbatas, sehingga hewan ini secara langsung akan terkena dampak dari perubahan lingkungan. Ada jenis-jenis yang mampu beradaptasi dengan perubahan lingkungan di sekitarnya, tetapi ada yang tidak mampu beradaptasi terhadap perubahan lingkungan, sehingga jenisnya tidak ditemukan lagi di wilayah tersebut.

Penurunan kualitas lingkungan dapat diidentifikasi dari perubahan komponen fisik, kimia dan biologi perairan di sekitar pantai.Perubahan komponen fisik dan kimia tersebut selain menyebabkan menurunnya kualitas perairan juga menyebabkan bagian dasar perairan (sedimen) menurun, yang dapat mempengaruhi kehidupan biota perairan terutama pada struktur komunitasnya (Odum, 1971; Warwick, 1993).Selain itu hewan benthos di suatu lingkungan juga dapat dipakai untuk menduga terjadi pencemaran perairan (American Public Health Association, 1989; Agard et.al, 1993).

Perairan negeri Tulehu merupakan wilayah pesisir yang memiliki ekosistem lamun yang berdampingan dengan sumberdaya hayati laut yang lainnya seperti mangrove, algae, mollusca, dan lain-lain. Ekosistem lamun pada perairan pantai negeri Tulehu memiliki penyebaran yang cukup luas. Selain itu, perairan pesisir pantai negeri Tulehu ini agak berbeda dengan perairan pantai pada umumnya karena perairan pantai negeri Tulehu ini dekat dengan sumber air panas. Umumnya komposisi mata air panas itu banyak mengandung komposisi belerang atau sulfur yang cukup tinggi (Dini dan Rainer, 2006).

Penelitian awal tentang komunitas lamun pada perairan ini telah dilakukan sebelumnya oleh Sangadji (2013) mengemukakan bahwa faktor lingkungan yaitu suhu dengan nilainya berkisar antara $26{ }^{\circ} \mathrm{C}-34{ }^{\circ} \mathrm{C}$ dan nilai salinitas berkisar antara $19 \%$ - $30 \%$. Tetapi informasi faktor lingkungan di ekosistem padang lamun tersebut masih terbatas yang memepengaruhi strukturnya. Oleh karena itu dilakukan penelitian dengan tujuan untuk mengetahui faktor lingkungan dan mengidntifikasi jenis-jenis dari filum mollusca dan filum echinodermata di perairan pantai negeri Tulehu. 


\section{METODE}

Penelitian ini berlangsung dari tanggal 9-10 Agustus 2014.Penelitian dengan metode kuadrat dengan teknik purporsive sampling. Alat dan bahan yang digunakan dalam penelitian ini adalah Rol meter, kamera Digital, GPS, Plastik sampel, Alat tulis, Tabel pengamatan, Kayu patok, Termometer, pH meter, Refraktometer, DO meter, Buku Identifikasi Bunjamin Dharma (2005), Setyastuti \& Rumahengan (2014), Alkohol 70\%, Aquades. Langkah-langkah prosedur penelitian ini antara lain dilakukan sebagai berikut: mengukur luasan area penelitian di mulai dengan pengukuran panjang dan lebar area sampling, menempatkan kuadrat secaraacaksebanyak 10x, mengukur faktor fisika dan faktor kimia lingkungan perairan (suhu, pH, salinitas dan oksigen terlarut), melakukan pengamatan terhadap jenisjenis dari filum echinodermata dan filum mollusca pada area sampling, mengambil contoh jenis-jenis dari filum echinodermata dan filum mollusca pada tiap area sampling kemudian dimasukkan kedalam kantong plastik untuk diidentifikasi dan dicatat dalam lembaran penelitian yang telah disediakan.

\section{HASIL DAN PEMBAHASAN Kondisi Faktor Lingkungan Suhu}

Hasil pengukuran suhu air laut pada kedua stasiun penelitian sangat bervariasi. Suhu air laut pada stasiun I berkisar antara $27-30^{\circ} \mathrm{C}$ dengan suhu tertinggi berada pada kuadran 6 yaitu $30^{\circ} \mathrm{C}$ sedangkan suhu terendah berada pada kuadran 8, 9 dan 10 yaitu $27^{\circ} \mathrm{C}$. Pada lokasi Stasiun II hasil pengukuran suhu air laut menunjukkan bahwa suhu tertinggi berada pada kuadran 1 yaitu $28^{\circ} \mathrm{C}$ sedangkan suhu terendah berada pada kuadran 9 yaitu $25^{\circ} \mathrm{C}$ (Gambar 1 ).

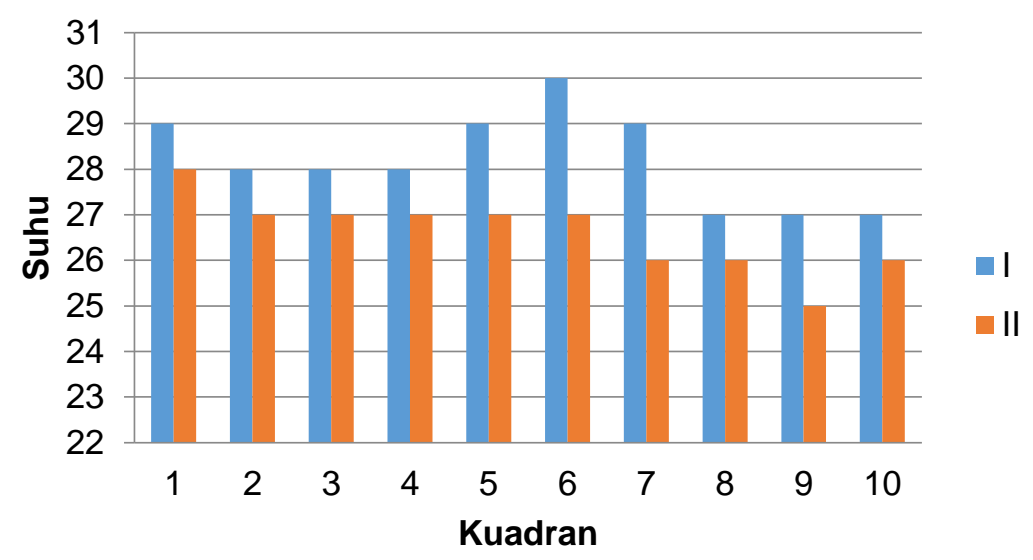

Gambar 1. Suhu Air Laut Pada Perairan Pantai Negeri Tulehu, Kabupaten Maluku Tengah.

Rendahnya nilai suhu perairan disebabkan karena pengambilan sampel dilakukan pada musim hujan, sehingga penurunan suhu dipermukaan perairan hingga dasaran berlangsung efektif. Suhu permukaan air cenderung lebih cepat berubah dibandingkan dengan suhu substrat karena air pada permukaan cenderung mengalir (Munarto, 2010). Menurut Sukarno (1981) dalam Heni (2007) bahwa suhu yang baik untuk pertumbuhan makrobenthos berkisar antara $25-31^{\circ} \mathrm{C}$. Suhu optimal beberapa jenis mollusca adalah $20^{\circ} \mathrm{C}$ dan apabila melampaui batas tersebut akan mengakibatkan berkurangnya aktivitas kehidupannya (Clark, 1986 dalam Heni, 2007). Suhu pada kedua Stasiun tersebut sesuai dengan suhu optimal yang mendukung kehidupan echinodermata maupun mollusca pada perairan pantai negeri Tulehu kecamatan Salahutu.

\section{pH (Derajat Keasaman dan Kebasaan)}

Hasil pengukuran $\mathrm{pH}$ air laut pada kedua stasiun penelitian yaitu pada Stasiun I menunjukkan bahwa nilai $\mathrm{pH}$ tertinggi berada pada kuadran 2 yakni 8,35 
sedangkan nilai $\mathrm{pH}$ terendah berada pada kuadran 6 yakni 6,70. Pada stasiun II menunjukkan bahwa nilai $\mathrm{pH}$ tertinggi berada pada kuadran 8 yakni 8,50 sedangkan nilai $\mathrm{pH}$ terendah berada pada kuadran 3 dan 6 yakni 7,55.

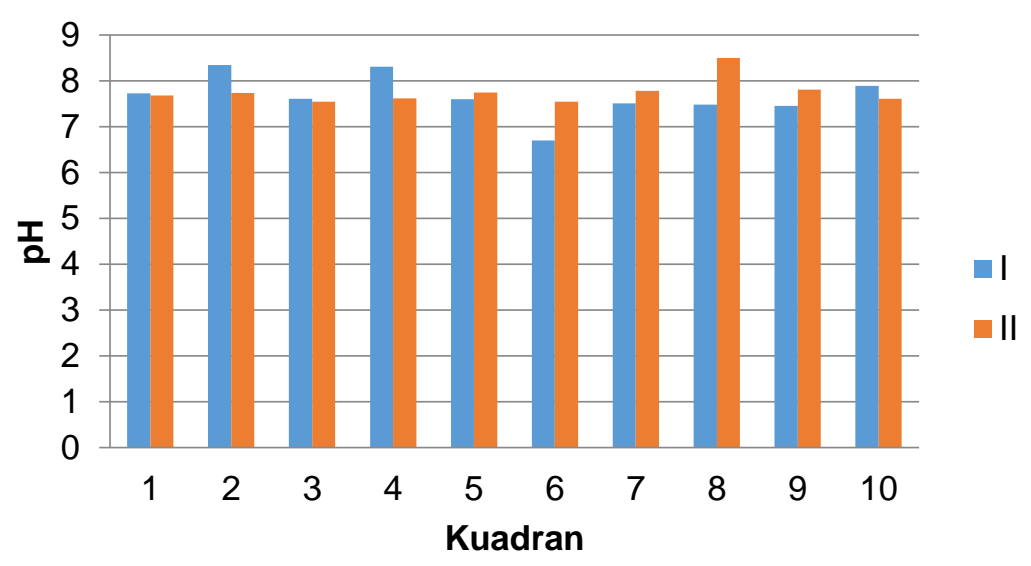

Gambar 2. pH Air Laut Pada Perairan Pantai Negeri Tulehu, Kabupaten Maluku Tengah.

Batas toleransi organisme terhadap $\mathrm{pH}$ bervariasi dan dipengaruhi banyak faktor antara lain suhu, oksigen terlarut, alkalinitas, adanya berbagai anion dan kation, jenis dan stadia organisme (Pescod, 1973 dalam Retnowati, 2003). Menurut Wardhana, 1994 dalam Windha, 2009 air laut normal yang memenuhi syarat untuk suatu kehidupan organisme laut mempunyai $\mathrm{pH}$ berkisar antara 6,5-7,5. Air limbah dan bahan buangan dari berbagai kegiatan manusia yang dibuang ke suatu badan perairan akan mengubah $\mathrm{pH}$ air yang pada akhirnya dapat mengganggu kehidupanorganisme di dalamnya.pHair laut pada kedua stasiun penelitian ini tergolong normal sesuai yang dinyatakan olehKepmen Negara LH (2004, No 51) bahwa kriteria penilaian baku mutu $\mathrm{pH}$ adalah 6,5 -8,5.

\section{Salinitas}

Pengukuran salinitas air laut pada kedua stasiun penelitian berkisar antara 14$31 \%$. Pada Stasiun I nilai Salinitas tertinggi berada pada kuadran 2 dan 3 yaitu 31\%o sedangkan nilai salinitas terendah berada pada kuadran 6-10 yaitu 25\%o. Pada stasiun II nilai salinitas tertinggi berada di kuadran 4 yaitu $30 \%$ sedangkan nilai salinitas terendah berada pada kuadran 3 yaitu 14\%.

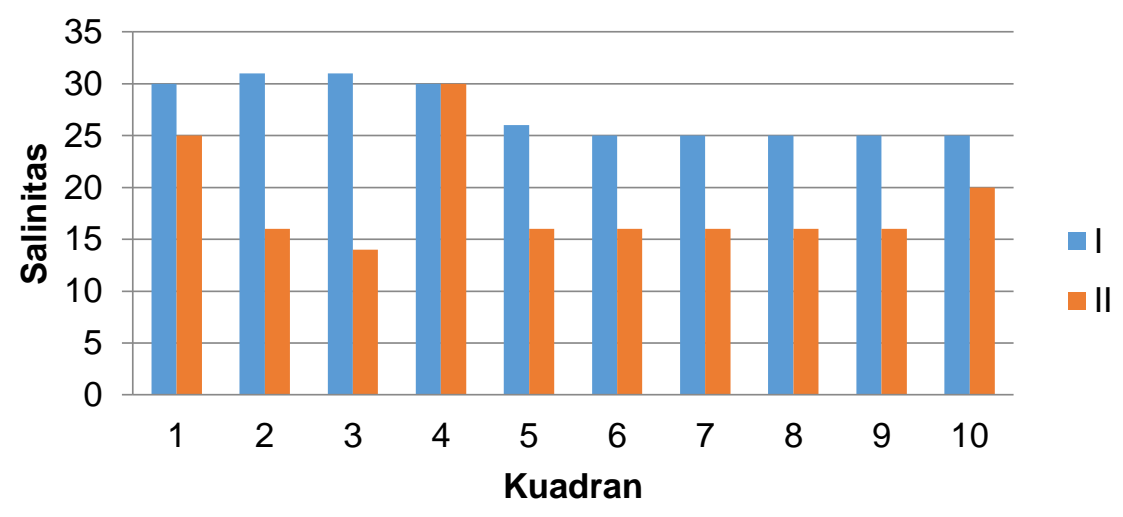

Gambar 3. Salinitas (\%) Air Laut Pada Perairan Pantai Negeri Tulehu, Kabupaten Maluku Tengah. 
Kondisi air laut di kedua stasiun memiliki salinitas berkisar 14-31\%o yang cenderung normal. Pantai Tulehu merupakan jenis pantai bercampur yaitu berpasir, berlumpur dan berkarang yang berupa patahan karang mati.Adanya karakteristik pantai berupa berbatu karang diketahui dapat dapat mengurangi penguapan, sehingga hal tersebut memberikan pengaruh juga pada tinggi rendahnya salinitas. Apabila penguapannya tinggi maka kadar garam tinggi. Hal lainnya yang berpengaruh pada salinitas adalah curah hujan, seperti yang dikatakan oleh (Nontji, 1993 dalam Katili, 2011) bahwa Salinitas perairan pantai menjadi turun karena dipengaruhi oleh curah hujan dan aliran sungai, sebaliknya daerah dengan penguapan yang kuat menyebabkan salinitas meningkat. Jadi, berdasarkan pengukuran salinitas air laut pada kedua stasiun penelitian masih cenderung normal karena masih dalam batas toleransi.

\section{Oksigen Terlarut (DO)}

Hasil pengukuran Oksigen Terlarut dalam air laut pada kedua stasiun penelitian yakni pada Stasiun I menunjukkan bahwa nilai tertinggi oksigen terlarut berada pada kuadran 2 dan 9 yaitu $8,5 \mathrm{mg} / \mathrm{l}$ sedangkan nilai terendah oksigen terlarut berada pada kuadran 4 yaitu $6,9 \mathrm{mg} / \mathrm{l}$. Hasil pengukuran Oksigen Terlarut dalam air laut yakni pada Stasiun II menunjukkan bahwa nilai Oksigen Terlarut tertinggi berada pada kuadran 7 yaitu $9,2 \mathrm{mg} / \mathrm{l}$ sedangkan nilai Oksigen terlarut terendah berada pada kuadran 2 yaitu $7,0 \mathrm{mg} / \mathrm{l}$.

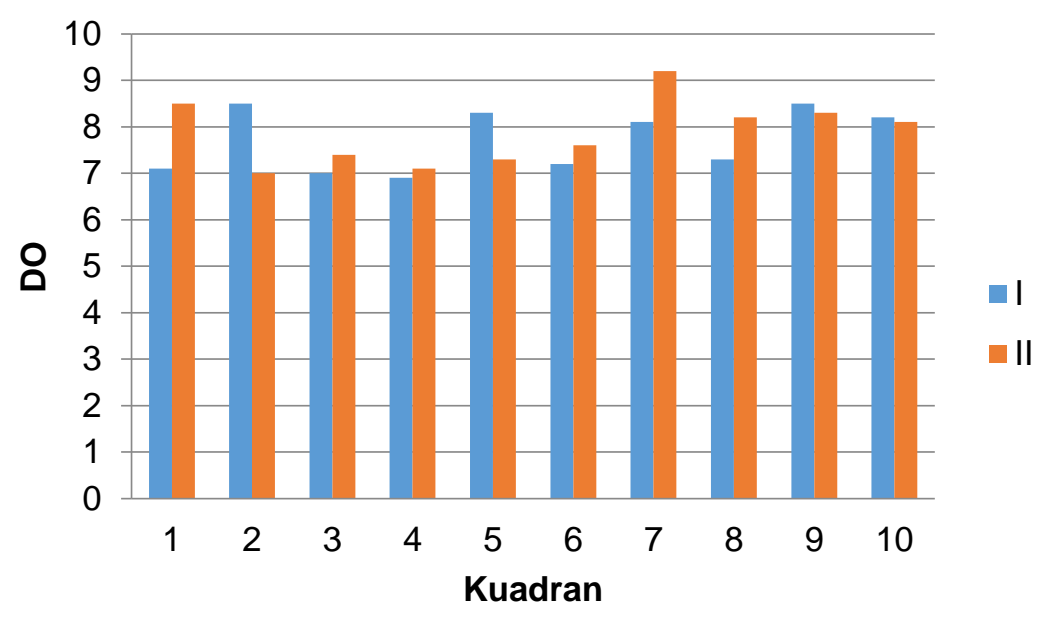

\section{Gambar 4. Oksigen Terlarut dalam air laut pada Perairan Pantai Negeri Tulehu, Kabupaten Maluku Tengah.}

Kondisi suhu yang semakin tinggi menyebabkan kelarutan gas akan semakin rendah dan kadar oksigen terlarut di permukaan air laut semakin berkurang (Simanjuntak, 2013). Oksigen terlarut dalam laut dimanfaatkan oleh organisme perairan untuk respirasi dan penguraian zat-zat organik oleh mikroorganisme. Sumber utama oksigen dalam air laut adalah udara melalui proses difusi dan dari proses fotosintesis fitoplankton. Oksigen terlarut merupakan salah satu penunjang utama kehidupan dilaut dan indikator kesuburan perairan. Beberapa faktor yang mempengaruhi kelarutan oksigen antara lain suhu, salinitas, pergerakkan massa air, tekanan atmosfir dan luas permukaan air. Berkurangnya oksigen dalam air antara lain disebabkan oleh pelepasan oksigen ke udara, aliran air tanah ke perairan, adanya zat besi, reduksi yang disebabkan oleh desakan gas lainnya dalam air, respirasi biota dan komposisi bahan organik (Nybakken, 1988 dalam Simanjuntak 2013). Jadi, Oksigen terlarut diperairan ini masih baik untuk kehidupan biota laut dengan kisaran konsentrasi masih dalam ambang batas Baku Mutu Kementerian Negara Lingkungan Hidup (KNLH, 2004 yaitu > $5 \mathrm{mg} / \mathrm{l})$. 


\section{Jenis-jenis Echinodermata yang ditemukan di Ekosistem Padang Lamun Perairan Pantai Negeri Tulehu \\ Hasil penelitian \\ jenis-jenis}

echinodermata di Ekosistem Padang Lamun perairan pantai negeri Tulehu kabupaten Maluku Tengah dan komposisi taksanya dapat dilihat pada tabel 1. Pada tabel 1 menunjukkan bahwa pada kedua stasiun penelitian hasil yang didapatkan 4 jenis echinodermata yaitu 1 jenis mewakili kelas Asteroidea, 1 jenis mewakili kelas Ophiuroidea, dan 2 jenis mewakili kelas Echinoidea.

Echinodermata merupakan salah satu biota yang berasosiasi kuat dengan padang lamun dan berperan dalam siklus rantai makanan di ekosistem tersebut (Yusrao \& Susetiono, 2005 dalam LIPI, 2011). Secara ekologis padang lamun memiliki peranan penting bagi habitat Echinodermata. Lamun berperan penting sebagai sumber pakan (feeding ground), tempat tinggal dan tempat asuhan larva Echinodermata agar tidak tersapu arus laut (nursery ground), serta tempat memijah (spawning ground) melindunginya dari serangan predator. Lamun juga menyokong rantai makanan dan penting dalam proses siklus nutrien serta sebagai pelindung pantai dari ancaman erosi ataupun abrasi (Romimohtarto dan Juwana, 1999dalam Jumanto 2013). Pada penelitian ini didapatkan 4 jenis echinodermata yang terbagi menjadi 3 kelas yaitu kelas Asteroidea, kelas Ophiuturoidea, dan kelas Echinoidea. Berikut ini diuraikan jenis-jenis echinodermata yang ditemukan pada kedua stasiun penelitian yaitu Archaster typicus, Ophiocoma erinaceus, Diadema setosum dan Laganum depressum. Dari 3 kelas yang ditemukan pada kedua stasiun penelitian jenis Archaster typicus yang banyak ditemukan karena berhabitat yang berpasir.

Jenis-Jenis Mollusca Yang Ditemukan di Ekosistem Padang Lamun Perairan Pantai Negeri Tulehu

Hasil penelitian jenis-jenis Mollusca di ekosistem padang lamun perairan pantai negeri Tulehu kabupaten Maluku Tengah dan komposisi taksanya dilihat pada tabel 2 . 
Biopendix, Volume 1, Nomor 2, Maret 2015, hlm. 117-125

Tabel 1. Komposisi Taksa Echinodermata yang ditemukan pada Ekosistem Padang Lamun Perairan Pantai Negeri Tulehu.

\begin{tabular}{|c|c|c|c|c|c|c|}
\hline \multirow{2}{*}{ Kelas } & \multirow{2}{*}{ Ordo } & \multirow{2}{*}{ Family } & \multirow{2}{*}{ Genus } & \multirow{2}{*}{ Spesies } & \multicolumn{2}{|c|}{ Stasiun Penelitian } \\
\hline & & & & & S-1 & S-2 \\
\hline Asteroidea & Valvatida & Archasteridae & Archaster & Archaster typicus & 7 & 1 \\
\hline Ophiuroidea & Ophiurida & Ophiocomidae & Ophiocoma & Ophiocoma erinaceus & - & 2 \\
\hline \multirow[t]{2}{*}{ Echinoidea } & Diadematoida & Diademadae & Diadema & Diadema setosum & - & 3 \\
\hline & Clypeasteroida & Laganidae & Laganum & Laganum depressum & 1 & 1 \\
\hline 3 & 4 & 4 & 4 & 4 & 8 & 7 \\
\hline
\end{tabular}

Keterangan: $\quad$ S-1: Stasiun 1

S-2: Stasiun 2 
Biopendix, Volume 1, Nomor 2, Maret 2015, hlm. 117-125

Tabel 2. Komposisi Taksa Mollusca Yang Ditemukan Pada Ekosistem Padang Lamun Perairan Pantai Negeri Tulehu.

\begin{tabular}{|c|c|c|c|c|c|c|}
\hline \multirow{2}{*}{ Kelas } & \multirow{2}{*}{ Ordo } & \multirow{2}{*}{ Family } & \multirow{2}{*}{ Genus } & \multirow{2}{*}{ Spesies } & \multicolumn{2}{|c|}{ Stasiun Penelitian } \\
\hline & & & & & S.1 & $\mathrm{S} .2$ \\
\hline \multirow[t]{2}{*}{ Bivalvia } & Veneroida & Veneridae & Pitar & Pitar citrinus & 1 & 1 \\
\hline & Veneroida & Cardiidae & Fragum & Fragum unedo & - & 1 \\
\hline \multirow[t]{17}{*}{ Gastropoda } & Cephalaspidea & Bullidae & Bulla & Bulla ampulla & 1 & 4 \\
\hline & Mesogastropoda & Cypraeidae & Cypraea & Cypraea moneta & 3 & 5 \\
\hline & & & & Cypraea annulus & 2 & 6 \\
\hline & & Naticidae & Polinices & Polinices lacteus & 3 & 4 \\
\hline & & Strombidae & Strombus & Strombus luhuanus & 2 & 4 \\
\hline & & & & Strombus urceus & 2 & 3 \\
\hline & & Cirithiidae & Rhinoclavis & Rhinoclavis fasciata & 2 & 2 \\
\hline & & Bursidae & Tutufa & Tutufa rubeta & 6 & 2 \\
\hline & Neogastropoda & Conidae & Conus & Conus miliaris & 2 & 2 \\
\hline & & Costellariidae & Vexillu & Vexillum plicarium & 2 & 3 \\
\hline & & Muricidae & Phyllocoma & Phyllocoma convoluta & 8 & 5 \\
\hline & & & Morula & Morula fusca & 7 & 2 \\
\hline & & Nassariidae & Nassarius & Nassarius pullus & 68 & 52 \\
\hline & & Olividae & Oliva & Oliva olive & 2 & 5 \\
\hline & & Terebridae & Terebra & Terebra quoygaimardi & 5 & 3 \\
\hline & & Tonnidae & Tonna & Tonna galea & 2 & 2 \\
\hline & Vetigastropoda & Tegulidae & Tectus & Tectus pyramis & 2 & 2 \\
\hline 2 & 5 & 14 & 15 & 19 & 120 & 108 \\
\hline
\end{tabular}




\section{KESIMPULAN}

Berdasarkan hasil penelitian yang telah dilakukan di Ekosistem Padang Lamun perairan pantai negeri Tulehu kabupaten Maluku Tengah maka dapat disimpulkan bahwa:

1. Faktor lingkungan yaitu suhu, salinitas, $\mathrm{pH}$, dan oksigen terlarut yang diukur pada kedua stasiun penelitian menunjukkan kisaran toleransi yang dapat mendukung kehidupan filum mollusca dan filumechinodermata.

2. Pada kedua stasiun penelitian ditemukan ditemukan 4 jenis dari filum echinodermata yang termasuk dalam 3 kelas yaitu kelas Echinoidea (bulu babi) diwakili oleh 2 jenis, kelas Asteroidea (bintang laut) diwakili oleh 1 jenis dan kelas Ophiuroidea (bintang mengular) diwakili 1 jenis. Selain itu, Pada kedua stasiun penelitian juga ditemukan 19 Jenis Mollusca yang terdiri dari 2 jenis dari kelas Bivalvia dan 17 jenis dari kelas Gastropoda.

\section{DAFTAR PUSTAKA}

Agard, J.B.R., J. Gobin, and R.M. Warwick, 1993. Analysis of marine macrobenthic community structure in relation to pollution, natural oil seepage and seasonal disturbance in a tropical environment (Trinidad, West Indies). Mar. Ecol. Prog. Ser. Vol 92: 233-243

American Public Health Association. 1989. Standart methods for tha examination of water and waste water. 17th ed. ALPHA AWWA (American WaterWorks Association) and WPCF (Water Pollution Control Federation), Washington DC: $3.464 \mathrm{pp}$

Dini, P dan Rainer, A.T. 2006. Tinjauan Geologi Mengenai Aktivitas Vulkanisme di Teluk Pria Laot di Pulau Weh Provinsi Nanggroe Aceh Darussalam. Jurnal Segara. Badan Riset Kelautan dan Perikanan.

Fonseca, M.S. and J.A. Cahalan., 1992.A preliminary evaluation of wave attenuation by four species of seagress. Estuarine, Coastal and Shelf Science 35:565-576.
Fonseca, M.S., J.S. Fisher., J.C. Zieman., 1982. Influence of the seagress, Zostera marina L., on current flow. Estuarine, Coastal and shelf Science 15: 351-364

Henni, W.M. 2007.Kajian Kualitas Perairan di Pantai Kota Bandar Lampung Berdasarkan Komunitas Hewan Makrobenthos.Thesis. Universitas Diponegogo. Semarang

Khouw, A, S. 2008. Metode dan Analisa Kuantitatif Dalam Bioekologi Laut. Pusat Pembelajaran dan Pengembangan Pesisir dan Laut (P4L)

Klumpp, D.W., R.K. Howard., D.A. Pollard., 1989. Trophodynamics and nutritional ecology of seagress communities. In Biology of Seagress: A Treatise on the Biology of Seagress with Special Reference to the Australian Region (eds. A.W.D. Larkum., A.J. Mc Comb., S.A. Sheperd), Elsevier, Amstrerdam, pp. 394-457.

Kementerian Negara Lingkungan Hidup No 51 tahun 2004 tentang Ketentuan Baku Mutu Air Laut untuk Biota Laut.

Kordi, K.M.G.H., 2011. Ekosistem Lamun (Seagress). Rineka Cipta. Jakarta.

McRoy, C.P. and C. Helfferich., 1980. Applied aspects of nseagress. In Handbook of Seagress Biology - An Ecological Approach (eds. R.C. Philips. and C.P. McRoy ), Garland Publications, New York, pp. 297-342.

Munarto, 2010. Studi Komunitas Gastropoda Disitu Salam Kampus Universitas Indonesia, Depok. Skripsi.Universitas Indonesia. Depok.

Odum, 1971.Fundamentals of Ecology.Sounders. Toronto.

Sangadji, 2013. Komunitas Lamun di Perairan Pantai Negeri Tulehu.Skripsi. Ambon: Universitas Pattimura.

Schramm. 1997. The Oxygen Factor (in pond).

http//www.hedley.ca/oxygen2.htm.10/0 4/09. $5 \mathrm{p}$.

Simanjuntak, M. 2013. Kualitas Perairan Gresik Jawa Timur Kandungan Zat Hara Oksigen Terlarut dan Derajat Keasaman.Pusat Penelitian Oseonografi-LIPI. Jakarta.

Warwick, R.M. 1993. Enviromental impact studies on marine communities: Pragmal considerations. Australian Journal of ecology. Vol 18, $63-80$. 